OPEN ACCESS

Edited by:

Lydia Gimenez-L/ort,

Autonomous University of Barcelona,

Spain

Reviewed by:

Thomas C. Foster,

University of Florida, United States

Min-Yu Sun,

Washington University in St. Louis,

United States

*Correspondence:

Hsien-Yuan Lane

hylane@gmail.com

Specialty section:

This article was submitted to

Neuropharmacology,

a section of the journal

Frontiers in Pharmacology

Received: 31 December 2018

Accepted: 29 April 2019

Published: 22 May 2019

Citation:

Lin C-H and Lane H-Y (2019) The

Role of N-Methyl-D-Aspartate

Receptor Neurotransmission and

Precision Medicine in Behavioral and

Psychological Symptoms

of Dementia.

Front. Pharmacol. 10:540.

doi: 10.3389/fphar.2019.00540

\section{The Role of N-Methyl-D-Aspartate Receptor Neurotransmission and Precision Medicine in Behavioral and Psychological Symptoms of Dementia}

\author{
Chieh-Hsin Lin ${ }^{1,2,3}$ and Hsien-Yuan Lane ${ }^{3,4,5 *}$
}

${ }^{1}$ Department of Psychiatry, Kaohsiung Chang Gung Memorial Hospital, Chang Gung University College of Medicine, Kaohsiung, Taiwan, ${ }^{2}$ School of Medicine, Chang Gung University, Taoyuan, Taiwan, ${ }^{3}$ Graduate Institute of Biomedical Sciences, China Medical University, Taichung, Taiwan, ${ }^{4}$ Department of Psychiatry and Brain Disease Research Center, China Medical University Hospital, Taichung, Taiwan, ${ }^{5}$ Department of Psychology, College of Medical and Health Sciences, Asia University, Taichung, Taiwan

While the world's population is aging, the prevalence of dementia and the associated behavioral and psychological symptoms of dementia (BPSD) rises rapidly. BPSD are associated with worsening of cognitive function and poorer prognosis. No pharmacological treatment has been approved to be beneficial for BPSD to date. Dysfunction of the $\mathrm{N}$-methyl-D-aspartate receptor (NMDAR)-related neurotransmission leads to cognitive impairment and behavioral changes, both of which are core symptoms of BPSD. Memantine, an NMDAR partial antagonist, is used to treat moderate to severe Alzheimer's disease (AD). On the other hand, a D-amino acid oxidase inhibitor improved early-phase $A D$. Whether to enhance or to attenuate the NMDAR may depend on the phases of dementia. It will be valuable to develop biomarkers indicating the activity of NMDAR, particularly in BPSD. In addition, recent reports suggest that gender difference exists in the treatment of dementia. Selecting subpopulations of patients with BPSD who are prone to improvement with treatment would be important. We reviewed literatures regarding the treatment of BPSD, focusing on the NMDAR-related modulation and precision medicine. Future studies examining the NMDAR modulators with the aid of potential biomarkers to tailor the treatment for individualized patients with BPSD are warranted.

Keywords: behavioral and psychological symptoms of dementia, Alzheimer's disease, N-methyl-D-aspartate receptor, precision medicine, gender difference

\section{INTRODUCTION}

Dementia is a severe neurodegenerative disorder, affecting $1.5 \%$ of the population at the age of 65 , and $>20 \%$ at the age of 85 (Ritchie and Kildea, 1995). The morbidity and mortality of dementia are high. For elderly people aged between 65 and 85 years, the prevalence rate of dementia doubles every 5 years (Fratiglioni et al., 1999). About 24.3 million people worldwide were diagnosed with dementia in 2005 (Ferri et al., 2005). In 2010, 35 million people had dementia worldwide (Brodaty et al., 2011). The population of people with dementia is estimated to be 
65 million by 2030 and 113 million by 2050 (Brodaty et al., 2011). The prevalence rate has been rising fast in the rapid-aging society (Prince et al., 2016).

The etiology of dementia remains unclear. Its increasing prevalence rate contributes to both a health and social problem, resulting in heavy caregiver burdens and economic impacts to the societies (2012 Alzheimer's Disease Facts and Figures, 2012). Age and female gender are two major risk factors for Alzheimer's disease (AD), which is the main cause of dementia; two-thirds of elderly people with $\mathrm{AD}$ are women. Even regarding the difference in longevity, studies suggest that women are still at a higher risk (Prince et al., 2016). Precision medicine approaches have advanced our understanding of the development and treatment of $\mathrm{AD}$ dementia. However, gender has not yet been adequately addressed by many of these approaches. More attention to gender differences will improve outcomes for people with dementia (Nebel et al., 2018). Previous research on NMDAR function has focused on cognition, particularly learning and memory. The current article focuses on mood or other psychological symptoms rather than memory.

\section{BEHAVIORAL AND PSYCHOLOGICAL SYMPTOMS OF DEMENTIA IS COMMON AND DETRIMENTAL IN DEMENTED PATIENTS}

One of the most troublesome domains of treating dementia is the behavioral and psychological symptoms of dementia (BPSD). The term "BPSD" was first described in late 1980s, and was then defined as "a term used to describe a heterogeneous range of psychological reactions, psychiatric symptoms, and behaviors occurring in people with dementia of any etiology" in the 1996 International Psychogeriatric Association (IPA) consensus conference (Finkel, 2003). BPSD can be classified into four domains: (1) disorders of thought content, including delusions, suspiciousness, etc. (Burns et al., 1990a); (2) disorders of perception, including misidentification syndromes, hallucinations, etc. (Burns et al., 1990b); (3) disorders of mood, including elevated mood, anxiety, depression, etc. (Burns et al., 1990c); and (4) disorders of behavior, including agitation, aggression, wandering, binge-eating, hyperorality, sexual disinhibition, urinary incontinence, etc. (Burns et al., 1990d).

BPSD is common among patients with dementia. Sixty-four percent of dementia patients revealed BPSD at initial evaluation (Devanand et al., 1997) and 90\% of them had BPSD over the whole dementia course (Steinberg et al., 2008). In Taiwan, the prevalence rate of all types of BPSD in patients with $A D$ is around 20-60\%, varying with different symptoms (Fuh, 2006). About $30-60 \%$ patients with $\mathrm{AD}$ have delusion, $21-26 \%$ hallucination, $35-76 \%$ anxiety, $22-50 \%$ depression, and $26-61 \%$ sleep abnormalities (Fuh, 2006).

The manifestations of BPSD vary with different types and stages of dementia. Mood symptoms are usually more common while psychotic symptoms are less common in vascular dementia (VaD) (O’Brien, 2003). In Eastern Asia, patients with $\mathrm{AD}$ had a high incidence of anxiety/phobia (61.2\%) and people with $\mathrm{VaD}$ had more paranoid and delusional ideation (71.9\%) and affective disturbance (46.9\%) (Chiu et al., 2006). Depression is more commonly observed in early stages of dementia while psychosis occurs more often in later stages (Paulsen et al., 2000; Savva et al., 2009). Furthermore, the severity of BPSD is often associated with the stage of dementia (Thompson et al., 2010). It is believed that BPSD without adequate treatment leads to poorer prognosis of dementia (Bourgeois et al., 1996; Shah and Allen, 1999; Brodaty et al., 2003; Huang et al., 2012).

\section{NO CURRENT MEDICATION IS APPROVED BY FOOD AND DRUG ADMINISTRATION FOR TREATING BEHAVIORAL AND PSYCHOLOGICAL SYMPTOMS OF DEMENTIA}

Despite the high prevalence rate of BPSD and its hazards in patients with dementia, there has not yet been medication that is effective and approved for the treatment of BPSD by the Food and Drug Administration (FDA) (Sink et al., 2005). The efficacy of antipsychotics for the treatment of BPSD is scanty (Schneider et al., 2006). In addition, there is safety concern for antipsychotics use in BPSD (Lee et al., 2004; Schneider et al., 2005). Furthermore, atypical antipsychotics may worsen the cognitive decline in patients with AD (Vigen et al., 2011), implying that antipsychotics may not be the best remedy for BPSD.

The efficacy of acetylcholinesterase inhibitors (AChEIs), which are the current main medication for $\mathrm{AD}$, for treating $\mathrm{BPSD}$ is controversial (Huang et al., 2012).

\section{N-METHYL-D-ASPARTATE RECEPTOR AND THE PATHOGENESIS OF DEMENTIA AND BEHAVIORAL AND PSYCHOLOGICAL SYMPTOMS OF DEMENTIA}

$\mathrm{N}$-methyl-D-aspartate receptors (NMDARs) exert multiple activities including two opposite ones: neurotoxicity and neurotrophic effects. Both NMDAR hypofunction and excitotoxicity are implicated in neurodegeneration. NMDAR activation is critical for synaptic plasticity, learning, and memory (Takehara et al., 2004; Zhao et al., 2005; Nakazawa et al., 2006; Gardoni et al., 2009). Attenuation of NMDAR neurotransmission can result in loss of neuronal plasticity and cognitive deficits (Collingridge and Bliss, 1995; Hawasli et al., 2007). Moreover, hypo-NMDAR function induced by NMDAR antagonists is neurotoxic, accounting for deterioration and brain atrophy (Olney and Farber, 1995).

NMDAR plays a vital role in the pathogenesis of $\mathrm{AD}$. Compared with healthy controls, individuals with $\mathrm{AD}$ have fewer NMDARs in the frontal cortex and hippocampus (Procter et al., 1989), lower CSF concentrations of excitatory amino 
acids (Martinez et al., 1993), lower serum levels of D-serine (Hashimoto et al., 2004), and reduced D-aspartate uptake (Lowe et al., 1990). In a mouse model of $\mathrm{AD}$, expression of surface NMDARs decreases in neurons (Snyder et al., 2005). Amyloid- $\beta$ peptide $(A \beta)$, which is the pathological hallmark for $A D$, can impair NMDAR signal transduction and synaptic function (Shankar et al., 2007; Yamin, 2009; Cisse et al., 2011). Apolipoprotein E4, an amyloid binding protein isoform related to the AD risk, also decreases NMDAR functions in patients with AD (Chen et al., 2010). Loss of presenilins reduces NMDAR-mediated responses and synaptic levels of NMDAR subunits, thereby affecting both short- and long-term plasticity in $\mathrm{AD}$ pathogenesis (Pimplikar et al., 2010).

\section{N-METHYL-D-ASPARTATE RECEPTOR INHIBITING AGENTS}

Memantine, an NMDAR partial antagonist and a drug for treating moderate-to-severe $\mathrm{AD}$, had conflicting data in the treatment of neuropsychiatric symptoms in dementia from randomized controlled trials (Reisberg et al., 2003; Tariot et al., 2004; Sink et al., 2005). In subsequent individual studies and pooled analyses (Gauthier et al., 2005, 2008; Wilcock et al., 2008), memantine had some benefits in the treatment of irritability/liability, agitation/aggression, and psychosis in patients with $\mathrm{AD}$, but stronger evidence from randomized controlled trials for BPSD is still lacking (Ballard et al., 2009). Lately, memantine's effect for BPSD has been found to be boosted by combination of citalopram, an antidepressant (Zhou et al., 2019). Of note, an initial reason for the use of memantine to treat $\mathrm{AD}$ is the hypothesis that activity of the NMDAR could be a mechanism for cell death (Foster et al., 2017). Thus, a potential fear is that enhancing NMDAR function would adversely affect the trajectory of dementia. This may be true for a subclass of dementia. On the other hand, another hypothesis (Foster et al., 2017) also indicates that NMDAR hypofunction is more detrimental to the progression of $\mathrm{AD}$ and that the use of memantine as a treatment may be more detrimental, producing cognitive impairments.

Inhibition of NMDAR function by NMDAR antagonists, such as ketamine or phencyclidine, produces psychotic/behavioral symptoms or relevant physiological reactions (Oranje et al., 2002; Carlen et al., 2012; Lin et al., 2012). However, the NMDAR antagonist ketamine has been shown to exhibit antidepressant effects (Duman, 2018). Since depression is one of the BPSD symptoms, whether ketamine and its derivatives, as rapid-acting antidepressants, are beneficial for BPSD treatment deserves further studies (Steenblock, 2018).

NMDAR dysfunction is also involved in ischemic stroke and vascular dementia. Although some studies revealed serum glutamate elevation in acute phase of ischemia stroke (Gusev et al., 2000; Marcoli et al., 2004), this increment of glutamate was only found 10-30 min after ischemic injury (Benveniste et al., 1984). Similarly, NMDAR hyperfunction occurs very briefly after brain injury; soon after the acute glutamate elevation, profound NMDAR hypofunction ensues and lasts for $>7$ days (Biegon et al., 2004). In fact, trials using NMDAR antagonists in the treatment of stroke have failed (Ikonomidou and Turski, 2002).

\section{N-METHYL-D-ASPARTATE RECEPTOR ENHANCING AGENTS}

Enhancing NMDA neurotransmission can improve memory and behavior symptoms of both dementia and schizophrenia (Goussakov et al., 2010; Lane et al., 2013). Clinical characteristics of BPSD, such as hallucinations, delusions, disorganized speech, and disturbing behavior, resemble positive symptoms of schizophrenia. Social withdrawal, apathy, alogia, and avolition, which resemble negative symptoms in schizophrenia, and behavior, sleep, or affective problems, are also frequently seen in patients with schizophrenia.

Augmentation through the NMDA-glycine site, a co-agonist site, is preferred to avoid the excitotoxicity (Coyle and Puttfarcken, 1993; Collingridge et al., 2013; Hackos and Hanson, 2017; Yao and Zhou, 2017; Hsu et al., 2018). Clinically, D-cycloserine, a partial agonist of the NMDA-glycine site, can improve cognitive functions of demented patients (Schwartz et al., 1996; Tsai et al., 1999). There are also several studies that suggest no benefit of D-cycloserine in AD patients (Randolph et al., 1994; Fakouhi et al., 1995; Tsai et al., 1998). Several possible reasons may explain the discrepancies; the lack of effect may be due to the dose or symptoms examined. Alternatively, the effects of D-cycloserine may depend on the stage of dementia. Since D-cycloserine appears to have benefits in improving cognition (Kalisch et al., 2009; Onur et al., 2010; Kuriyama et al., 2011a,b; Feld et al., 2013), it may have differential effects on mood and learning depending on the stage of dementia.

Since D-serine is more potent than D-cycloserine and glycine as the glycine co-agonist site of the NMDAR (Heresco-Levy, 2005; Lin et al., 2012), one method to enhance NMDAR function is to inhibit activity of D-amino acid oxidase (DAAO), which is responsible for degrading $\mathrm{D}$-serine and $\mathrm{D}$-alanine (Fukui and Miyake, 1992; Vanoni et al., 1997). One of the candidates of DAAO inhibitors is benzoic acid and its salt, sodium benzoate. They can inhibit DAAO activity and thereby raise synaptic concentrations of D-serine both in vitro and in animal studies (Van den Berghe-Snorek and Stankovich, 1985).

Several clinical trials have shown the potential of NMDAR-enhancing agents [for example, sarcosine (a glycine transporter I inhibitor) and sodium benzoate] in alleviating psychotic symptoms of schizophrenia (Lane et al., 2005, 2006, 2008, 2010, 2013; Lin et al., 2018b), in treating major depressive disorder (Huang et al., 2013), in decreasing oppositional defiant disorder symptoms of attention deficit hyperactivity disorder (Tzang et al., 2016), and in reducing neuropsychiatric symptoms of Parkinson's disease with dementia (Tsai et al., 2014).

In a 6-week, randomized, double-blind, placebo-controlled trial in patients with schizophrenia ( $<65$ year old), sodium benzoate ( $1 \mathrm{~g} /$ day) adjunctive therapy was significantly better than placebo in reducing positive and negative symptoms 
and in improving Global Assessment of Functioning, and revealed favorable safety (Lane et al., 2013). The effect size of sodium benzoate treatment for Positive and Negative Syndrome Rating Scale (PANSS) total score from baseline to endpoint was 1.26, much higher than effect size (0.51) of sarcosine adjuvant therapy for the PANSS total score in chronic schizophrenia patients (Tsai et al., 2004). It is noteworthy that sodium benzoate treatment was significantly better than placebo in improving cognitive functions, such as processing speed and visual memory (Lane et al., 2013). In another clinical trial on mild cognitive impairment or mild $\mathrm{AD}$, a total of 60 patients were randomized into sodium benzoate or placebo group. The patients also tolerated sodium benzoate $250-1,500 \mathrm{mg} /$ day well without evident side effects. Interestingly, the patients taking sodium benzoate improved more in Alzheimer's Disease Assessment Scale-cognitive subscale (ADAS-cog) and other cognitive assessments than placebo (Lin et al., 2014).

Of note, a single nucleotide polymorphism (rs2153674) in the G72 (D-amino acid oxidase activator, DAOA, responsible for metabolism of D-serine) gene is associated with the occurrence of psychotic symptoms in patients with AD (Di Maria et al., 2009). In addition, affinity of the glycine recognition sites of NMDARs was related with the anxiety tone, one domain of BPSD, in patients with AD (Tsang et al., 2008). Therefore, it is possible that NMDAR-enhancing agents, which have been demonstrated to be effective in treating schizophrenia, depression, and other psychiatric symptoms, could also be used in the treatment of BPSD.

Moreover, stimulation of NMDARs 24 and $48 \mathrm{~h}$ after brain injury could attenuate neurological deficits and improve cognitive performance, implying that NMDAR function is crucial for neural repair in subacute or chronic stroke (Biegon et al., 2004). The aforementioned studies suggest the potential use of DAAO inhibitors for the treatment of BPSD.

\section{GENDER DIFFERENCE IN N-METHYL- D-ASPARTATE RECEPTOR FUNCTION}

Age and female gender are two major risk factors for $\mathrm{AD}$; two-thirds of elderly people with AD are women. Even regarding the difference in longevity, studies suggest that women are still at a higher risk (Prince et al., 2016). However, gender has not yet been adequately addressed by many of these approaches. More attention to gender differences will improve outcomes for demented people (Nebel et al., 2018).

A previous study showed that female rats were much more susceptible to NMDAR modulation than males (Honack and Loscher, 1993). Another study found that the average density of NMDAR currents was 2.8-fold larger in dorsal root ganglia of female rats than that of male rats, and that addition of 17 - $B$-estradiol (E2) increased NMDAR currents by $55 \%$ in female neurons, but only $19 \%$ in male, indicating sex differences in the activity and estrogen modulation of NMDAR (McRoberts et al., 2007). Further, estrogen also plays a role in NMDAR function during aging (Vedder et al., 2014; Bean et al., 2015).
E2 treatment can enhance the long-term potentiation (LTP) magnitude at CA3-CA1 synapses, NMDAR/AMPAR ratio, GluN2B-mediated NMDAR current, hippocampal CA1 dendritic spine density, and novel object recognition (NOR), a task that requires hippocampal NMDARs, in female rats during a critical period between 9 and 15 months, but not at 19 months post-ovariectomy (OVX) (Smith et al., 2010; Vedder et al., 2014).

Sex hormones were found to modulate hippocampal NMDAR expression in mice (McCarthny et al., 2018), and interact with circulating antioxidants in human blood (Bellanti et al., 2013). Noteworthily, benzoic acid ester of estrone, a precursor of estradiol, has prolonged duration of action (Labhart, 2012), suggesting that benzoate may interact with female sex hormone (Lemini et al., 1997).

Whether benzoate can improve cognitive function and the behavioral symptoms in patients with BPSD in a gender-specific manner deserves investigation. Further study is needed to verify the possible mediating roles of sex hormones in benzoate effect for dementia and its associated BPSD.

\section{HUNTING FOR PERIPHERAL BIOLOGICAL MARKERS OF DEMENTIA}

At present, the diagnosis of dementia mainly relies on clinical manifestation. There was no satisfactory laboratory test from the peripheral approach for the diagnosis of dementia. There have been lots of postmortem brain studies in fields of $\mathrm{AD}$ and related neurodegenerative disorders (Chen et al., 2001; Stewart et al., 2001). It was highly concerning that RNA expressions might be affected by many factors (e.g., coma. hypoxia) under postmortem condition (Tomita et al., 2004). A peripheral measurable marker is needed, to enable a simple, more rapid, and more accurate diagnosis and monitoring (Ilani et al., 2001; Lin et al., 2017a).

It is proposed that white blood cells and lymphocytes may serve as neural probes since there are similarities of signal transduction and receptor expression between peripheral blood cells and neurons/glia (Gladkevich et al., 2004). A blood-derived sample will be a more feasible alternative to brain tissue biopsy if the gene expressions are synchronized in both (Tsuang et al., 2005). For example, Hye et al. reported that glycogen synthase kinase- 3 was increased in both $\mathrm{AD}$ and mild cognitive impairment patients (Hye et al., 2005). However, some molecules would be not suitable for serving as biomarkers, due to the large overlap between patient and control groups.

\section{POTENTIAL PERIPHERAL PREDICTORS FOR TREATMENT RESPONSE OF N-METHYL-D-ASPARTATE RECEPTOR ENHANCERS}

Precision medicine approaches have advanced our understanding of the development and treatment of dementia. Many genes 
which lie in different pathways were found to be associated with susceptibility of dementia and/or psychosis. Genes on the pathways, which are associated with the metabolism of $\mathrm{D}$-amino acids, glycine and glutamate, may be able to regulate the NMDAR function.

\section{D-Amino Acids Metabolism}

D-amino acid oxidase activator (DAOA, or named G72) protein regulates DAAO activity (Goldberg et al., 2006), enhances metabolism of $\mathrm{D}$-serine and $\mathrm{D}$-alanine, and can attenuate NMDAR neurotransmission. D-serine is generated from $\mathrm{L}$-serine by serine racemase (SRR) (Wolosker et al., 1999) and degraded by DAAO (Nagata, 1992). Over the past few years, more than 30 studies have demonstrated the association of DAAO and G72 with schizophrenia (Boks et al., 2007). Diminished D-serine along with elevation in L-serine also suggests the dysfunction of SRR activity (Hashimoto et al., 2003). DAAO is implicated in oxidative stress (Stegman et al., 1998; Lu et al., 2012). Studies indicated that the DAAO level in peripheral blood increased with the severity of cognitive deficits in the elderly (Lin et al., 2017b) and decreased after 6-week treatment of sodium benzoate (a DAAO inhibitor) in patients with schizophrenia (Lin et al., 2018a). It is hypothesized that G72, DAAO, and SRR, which regulate the metabolism of the main co-agonist of the NMDAR, D-serine, are associated with dementia and its BPSD.

\section{Glycine Metabolism}

Glycine, a co-agonist of the NMDAR, is abundant throughout the brain and serves as a major inhibitory neurotransmitter in the hindbrain. Serine hydroxymethyltransferase (SHMT) is the enzyme which cleaves serine into glycine (Cossins et al., 1976). The activity of SHMT was significantly lower in psychotic individuals than in nonpsychotic ones (Waziri et al., 1985). Phosphoserine aminotransferase (PSAT) enzyme accounts for the serine biosynthesis (Pestka and Delwiche, 1981). Patients with PSAT deficiency manifest a broad spectrum of neuropsychiatric symptoms clinically (Hart et al., 2007). Glycine C-acetyltransferase, also known as GCAT, acts in concert with L-threonine 3-dehydrogenase (TDH) in the degradation of threonine to form glycine (McGilvray and Morris, 1969). Aminomethyltransferase (AMT) is an enzyme that catabolizes the creation of methylenetetrahydrofolate. It is part of the glycine decarboxylase complex.

\section{Glutamate Metabolism}

Glutamate is the most abundant amino acid neurotransmitter in the mammalian brain. Glutamatergic neurotransmission has drawn attention for its role in the pathophysiology of many mental illnesses (Lin et al., 2012). The extracellular concentration of glutamate is regulated by the action of transporter proteins, which include glial high-affinity glutamate transporter, member 3 (SLC1A3) (Kanai and Hediger, 2004) and neutral amino acid transporter (ASCT1) (Weiss et al., 2005). Glutamate receptor, metabotropic 3 (GRM3) (Carter, 2007) and glutamate receptor, ionotropic, kainate 1 (GluR5) (Wisden and Seeburg, 1993) are among the genes related to the glutamatergic neurotransmission systems. Glutamate decarboxylase 1 (GAD1), encoding the
$67-\mathrm{kDa}$ isoform of glutamate decarboxylase, is the key enzyme for GABA biosynthesis and is expressed at altered levels in postmortem brain of subjects diagnosed with schizophrenia and related psychotic disorders (Straub et al., 2007).

Increased oxidative stress also contributes to aging processes and neurodegenerative diseases (Gallagher et al., 1996; Serrano and Klann, 2004; Butterfield and Halliwell, 2019), while free radicals damage cells and tissues (Harman, 1956). Antioxidants may help to prevent and reverse cognitive deficits induced by free radicals (Guerrero et al., 1999; Bickford et al., 2000; Tardiolo et al., 2018). Studies indicate a link among age-related NMDAR dysfunction, oxidative stress, and senescence and related cognitive decline (Guidi et al., 2015; Kumar, 2015).

\section{SUMMARY}

BPSD appears the hardest-to-treat domain of dementia. Non-pharmacological approaches are the mainstream treatment; however, psychotropics are still needed for a substantial portion of patients. While second-generation antipsychotics have been widely used for the treatment for BPSD, their adverse effects generally offset the benefits. To date, no pharmacological approach has been approved for the treatment of BPSD.

Lately, NMDAR activating strategies, such as DAAO inhibition, have been demonstrated to benefit early-phase dementia as well as psychotic disorders such as schizophrenia. Whether such a novel medical route can also improve BPSD (or a fraction of it, with the aid of molecular precision medicine) deserves studies.

Since BPSD is difficult to treat, it is important to identify subpopulations that tend to respond to certain treatments. Recent studies suggest that the NMDAR expression may be different between female and male species. Genes involved in the pathways associated with the regulation of NMDAR might be altered in BPSD, and have potential to be developed as biomarkers for detecting dementia and predicting the treatment response.

In summary, the review addressed the NMDAR-related modulation and precision medicine in BPSD. Future studies examining the NMDAR modulators with the aid of potential biomarkers to tailor the treatment for individualized patients with BPSD will advance the treatment of BPSD.

\section{AUTHOR CONTRIBUTIONS}

C-HL and H-YL determined the outline, reviewed the literature, and wrote and approved the manuscript.

\section{FUNDING}

This work was funded by the Ministry of Science and Technology, Taiwan (MOST 107-2314-B-039-039), National Health Research Institutes (NHRI-EX107-10731NI), China Medical University Hospital, Taiwan (DMR-108-218), and Taiwan Ministry of Health and Welfare Clinical Trial and Research Center of Excellence (MOHW107-TDU-B-212-123004). 


\section{REFERENCES}

Alzheimer Association (2012). 2012 Alzheimer's Disease Facts and Figures. Alzheimer's Dement. 8, 131-168. doi: 10.1016/j.jalz.2012.02.001

Ballard, C., Corbett, A., Chitramohan, R., and Aarsland, D. (2009). Management of agitation and aggression associated with Alzheimer's disease: controversies and possible solutions. Curr. Opin. Psychiatry 22, 532-540. doi: 10.1080/ 13506280902978477

Bean, L. A., Kumar, A., Rani, A., Guidi, M., Rosario, A. M., Cruz, P. E., et al. (2015). Re-opening the critical window for estrogen therapy. J. Neurosci. 35, 16077-16093. doi: 10.1523/JNEUROSCI.1890-15.2015

Bellanti, F., Matteo, M., Rollo, T., De Rosario, F., Greco, P., Vendemiale, G., et al. (2013). Sex hormones modulate circulating antioxidant enzymes: impact of estrogen therapy. Redox Biol. 1, 340-346. doi: 10.2500/aap.2013.34.0018

Benveniste, H., Drejer, J., Schousboe, A., and Diemer, N. H. (1984). Elevation of the extracellular concentrations of glutamate and aspartate in rat hippocampus during transient cerebral ischemia monitored by intracerebral microdialysis. J. Neurochem. 43, 1369-1374.

Bickford, P. C., Gould, T., Briederick, L., Chadman, K., Pollock, A., Young, D., et al. (2000). Antioxidant-rich diets improve cerebellar physiology and motor learning in aged rats. Brain Res. 866, 211-217. doi: 10.1016/S0006-8993(00)02280-0

Biegon, A., Fry, P. A., Paden, C. M., Alexandrovich, A., Tsenter, J., and Shohami, E. (2004). Dynamic changes in N-methyl-D-aspartate receptors after closed head injury in mice: implications for treatment of neurological and cognitive deficits. Proc. Natl. Acad. Sci. USA 101, 5117-5122. doi: 10.2174/1381612043384196

Boks, M. P., Rietkerk, T., van de Beek, M. H., Sommer, I. E., de Koning, T. J., and Kahn, R. S. (2007). Reviewing the role of the genes G72 and DAAO in glutamate neurotransmission in schizophrenia. Eur. Neuropsychopharmacol. 17, 567-572. doi: 10.1177/0267659107086656

Bourgeois, M. S., Schulz, R., and Burgio, L. (1996). Interventions for caregivers of patients with Alzheimer's disease: a review and analysis of content, process, and outcomes. Int. J. Aging Hum. Dev. 43, 35-92.

Brodaty, H., Ames, D., Snowdon, J., Woodward, M., Kirwan, J., Clarnette, R., et al. (2003). A randomized placebo-controlled trial of risperidone for the treatment of aggression, agitation, and psychosis of dementia. J. Clin. Psychiatry 64, 134-143. doi: 10.1046/j.0309-2402.2003.02848.x

Brodaty, H., Breteler, M. M., Dekosky, S. T., Dorenlot, P., Fratiglioni, L., Hock, C., et al. (2011). The world of dementia beyond 2020. J. Am. Geriatr. Soc. 59, 923-927. doi: 10.1016/S0140-6736(11)61031-3

Burns, A., Jacoby, R., and Levy, R. (1990a). Psychiatric phenomena in Alzheimer's disease. I: disorders of thought content. Br. J. Psychiatry 157, 72-76, 92-74.

Burns, A., Jacoby, R., and Levy, R. (1990b). Psychiatric phenomena in Alzheimer's disease. II: disorders of perception. Br. J. Psychiatry 157, 76-81, 92-74.

Burns, A., Jacoby, R., and Levy, R. (1990c). Psychiatric phenomena in Alzheimer's disease. III: disorders of mood. Br. J. Psychiatry 157, 81-86, 92-84.

Burns, A., Jacoby, R., and Levy, R. (1990d). Psychiatric phenomena in Alzheimer's disease. IV: disorders of behaviour. Br. J. Psychiatry 157, 86-94.

Butterfield, D. A., and Halliwell, B. (2019). Oxidative stress, dysfunctional glucose metabolism and Alzheimer disease. Nat. Rev. Neurosci. 20, 148-160. doi: 10.1186/s40425-019-0552-x

Carlen, M., Meletis, K., Siegle, J. H., Cardin, J. A., Futai, K., Vierling-Claassen, D., et al. (2012). A critical role for NMDA receptors in parvalbumin interneurons for gamma rhythm induction and behavior. Mol. Psychiatry 17, 537-548. doi: $10.1016 /$ j.brainres.2012.06.059

Carter, C. J. (2007). eIF2B and oligodendrocyte survival: where nature and nurture meet in bipolar disorder and schizophrenia? Schizophr. Bull. 33, 1343-1353. doi: $10.1093 / \mathrm{schbul} / \mathrm{sbm} 007$

Chen, B., Dowlatshahi, D., MacQueen, G. M., Wang, J. F., and Young, L. T. (2001). Increased hippocampal BDNF immunoreactivity in subjects treated with antidepressant medication. Biol. Psychiatry 50, 260-265. doi: 10.1023/ A: 1008192221674

Chen, Y., Durakoglugil, M. S., Xian, X., and Herz, J. (2010). ApoE4 reduces glutamate receptor function and synaptic plasticity by selectively impairing ApoE receptor recycling. Proc. Natl. Acad. Sci. USA 107, 12011-12016. doi: 10.1073/pnas.0914984107

Chiu, M. J., Chen, T. F., Yip, P. K., Hua, M. S., and Tang, L. Y. (2006). Behavioral and psychologic symptoms in different types of dementia. J. Formosan Med. Assoc. 105, 556-562. doi: 10.1155/BSB/2006/35809
Cisse, M., Halabisky, B., Harris, J., Devidze, N., Dubal, D. B., Sun, B., et al. (2011). Reversing EphB2 depletion rescues cognitive functions in Alzheimer model. Nature 469, 47-52. doi: 10.1038/nature09635

Collingridge, G. L., and Bliss, T. V. (1995). Memories of NMDA receptors and LTP. Trends Neurosci. 18, 54-56. doi: 10.1016/0165-0270(94)00187-L

Collingridge, G. L., Volianskis, A., Bannister, N., France, G., Hanna, L., Mercier, M., et al. (2013). The NMDA receptor as a target for cognitive enhancement. Neuropharmacology 64, 13-26. doi: 10.1016/j.cub.2013.09.059

Cossins, E. A., Chan, P. Y., and Combepine, G. (1976). One-carbon metabolism in Neurospora crassa wild-type and in mutants partially deficient in serine hydroxymethyltransferase. Biochem. J. 160, 305-314. doi: 10.1042/bj1600305

Coyle, J. T., and Puttfarcken, P. (1993). Oxidative stress, glutamate, and neurodegenerative disorders. Science 262, 689-695.

Devanand, D. P., Jacobs, D. M., Tang, M. X., Del Castillo-Castaneda, C., Sano, M., Marder, K., et al. (1997). The course of psychopathologic features in mild to moderate Alzheimer disease. Arch. Gen. Psychiatry 54, 257-263.

Di Maria, E., Bonvicini, C., Bonomini, C., Alberici, A., Zanetti, O., and Gennarelli, M. (2009). Genetic variation in the G720/G30 gene locus (DAOA) influences the occurrence of psychotic symptoms in patients with Alzheimer's disease. JAD 18, 953-960. doi: 10.3233/JAD-2009-1194

Duman, R. S. (2018). Ketamine and rapid-acting antidepressants: a new era in the battle against depression and suicide. F1000Res 7. doi: 10.12688/ f1000research.14344.1

Fakouhi, T. D., Jhee, S. S., Sramek, J. J., Benes, C., Schwartz, P., Hantsburger, G., et al. (1995). Evaluation of cycloserine in the treatment of Alzheimer's disease. J. Geriatr. Psychiatry Neurol. 8, 226-230. doi: 10.1177/089198879500800405

Feld, G. B., Lange, T., Gais, S., and Born, J. (2013). Sleep-dependent declarative memory consolidation-unaffected after blocking NMDA or AMPA receptors but enhanced by NMDA coagonist D-cycloserine. Neuropsychopharmacology 38, 2688-2697. doi: 10.1038/npp.2013.179

Ferri, C. P., Prince, M., Brayne, C., Brodaty, H., Fratiglioni, L., Ganguli, M., et al. (2005). Global prevalence of dementia: a Delphi consensus study. Lancet 366, 2112-2117. doi: 10.1021/jp052672n

Finkel, S. I. (2003). Behavioral and psychologic symptoms of dementia. Clin. Geriatr. Med. 19, 799-824. doi: 10.1016/S0749-0690(03)00046-6

Foster, T. C., Kyritsopoulos, C., and Kumar, A. (2017). Central role for NMDA receptors in redox mediated impairment of synaptic function during aging and Alzheimer's disease. Behav. Brain Res. 322, 223-232. doi: 10.1016/j. bbr.2016.05.012

Fratiglioni, L., De Ronchi, D., and Aguero-Torres, H. (1999). Worldwide prevalence and incidence of dementia. Drugs Aging 15, 365-375. doi: 10.2165/ 00002512-199915050-00004

Fuh, J. L. (2006). Study of behavioral and psychological symptoms of dementia in Taiwan. Acta Neurol. Taiwanica 15, 154-160. doi: 10.1016/j. talanta.2005.06.057

Fukui, K., and Miyake, Y. (1992). Molecular cloning and chromosomal localization of a human gene encoding D-amino-acid oxidase. J. Biol. Chem. 267, 18631-18638. doi: 10.11405/nisshoshi1964.89.2798

Gallagher, M., Landfield, P. W., McEwen, B., Meaney, M. J., Rapp, P. R., Sapolsky, R., et al. (1996). Hippocampal neurodegeneration in aging. Science 274, 484-485. doi: 10.7182/prtr.1.6.4.b8211n7433573121

Gardoni, F., Mauceri, D., Malinverno, M., Polli, F., Costa, C., Tozzi, A., et al. (2009). Decreased NR2B subunit synaptic levels cause impaired long-term potentiation but not long-term depression. J. Neurosci. 29, 669-677. doi: 10.1523/JNEUROSCI.3921-08.2009

Gauthier, S., Loft, H., and Cummings, J. (2008). Improvement in behavioural symptoms in patients with moderate to severe Alzheimer's disease by memantine: a pooled data analysis. Int. J. Geriatric Psychiatry 23, 537-545 doi: $10.1577 / \mathrm{H} 07-037.1$

Gauthier, S., Wirth, Y., and Mobius, H. J. (2005). Effects of memantine on behavioural symptoms in Alzheimer's disease patients: an analysis of the neuropsychiatric inventory (NPI) data of two randomised, controlled studies. Int. J. Geriatric Psychiatry 20, 459-464. doi: 10.1016/S0840-4704(10)60067-1

Gladkevich, A., Kauffman, H. F., and Korf, J. (2004). Lymphocytes as a neura probe: potential for studying psychiatric disorders. Prog. NeuroPsychopharmacol. Biol. Psychiatry 28, 559-576. doi: 10.1016/j.pnpbp.2004.01.009 Goldberg, T. E., Straub, R. E., Callicott, J. H., Hariri, A., Mattay, V. S., Bigelow, L., et al. (2006). The G72/G30 gene complex and cognitive abnormalities 
in schizophrenia. Neuropsychopharmacology 31, 2022-2032. doi: 10.1038/ sj.npp.1301049

Goussakov, I., Miller, M. B., and Stutzmann, G. E. (2010). NMDA-mediated $\mathrm{Ca}(2+)$ influx drives aberrant ryanodine receptor activation in dendrites of young Alzheimer's disease mice. J. Neurosci. 30, 12128-12137. doi: 10.1523/ JNEUROSCI.2474-10.2010

Guerrero, A. L., Dorado-Martinez, C., Rodriguez, A., Pedroza-Rios, K., Borgonio-Perez, G., and Rivas-Arancibia, S. (1999). Effects of vitamin E on ozone-induced memory deficits and lipid peroxidation in rats. NeuroReport 10, 1689-1692.

Guidi, M., Kumar, A., and Foster, T. C. (2015). Impaired attention and synaptic senescence of the prefrontal cortex involves redox regulation of NMDA receptors. J. Neurosci. 35, 3966-3977. doi: 10.1109/EMBC.2015.7319785

Gusev, E. I., Skvortsova, V. I., Dambinova, S. A., Raevskiy, K. S., Alekseev, A. A., Bashkatova, V. G., et al. (2000). Neuroprotective effects of glycine for therapy of acute ischaemic stroke. Cerebrovasc. Dis. 10, 49-60. doi: 10.1159/000016025

Hackos, D. H., and Hanson, J. E. (2017). Diverse modes of NMDA receptor positive allosteric modulation: mechanisms and consequences. Neuropharmacology 112, 34-45. doi: 10.1016/j.neuropharm.2016.07.037

Harman, D. (1956). Aging: a theory based on free radical and radiation chemistry. J. Gerontol. 11, 298-300. doi: 10.1017/S0022215100053093

Hart, C. E., Race, V., Achouri, Y., Wiame, E., Sharrard, M., Olpin, S. E., et al. (2007). Phosphoserine aminotransferase deficiency: a novel disorder of the serine biosynthesis pathway. Am. J. Hum. Genet. 80, 931-937. doi: 10.1086/517888

Hashimoto, K., Fukushima, T., Shimizu, E., Komatsu, N., Watanabe, H., Shinoda, N., et al. (2003). Decreased serum levels of D-serine in patients with schizophrenia: evidence in support of the N-methyl-D-aspartate receptor hypofunction hypothesis of schizophrenia. Arch. Gen. Psychiatry 60, 572-576. doi: 10.1001/archpsyc.60.6.572

Hashimoto, K., Fukushima, T., Shimizu, E., Okada, S., Komatsu, N., Okamura, N., et al. (2004). Possible role of D-serine in the pathophysiology of Alzheimer's disease. Prog. Neuro-Psychopharmacol. Biol. Psychiatry 28, 385-388. doi: 10.1093/ nass/48.1.235

Hawasli, A. H., Benavides, D. R., Nguyen, C., Kansy, J. W., Hayashi, K., Chambon, P., et al. (2007). Cyclin-dependent kinase 5 governs learning and synaptic plasticity via control of NMDAR degradation. Nat. Neurosci. 10, 880-886. doi: 10.1002/biot.200700093

Heresco-Levy, U. (2005). Glutamatergic neurotransmission modulators as emerging new drugs for schizophrenia. Expert Opin. Emerg. Drugs 10, 827-844. doi: $10.1517 / 14728214.10 .4 .827$

Honack, D., and Loscher, W. (1993). Sex differences in NMDA receptor mediated responses in rats. Brain Res. 620, 167-170. doi: 10.1016/0006-8993(93)90287-W

Hsu, W. Y., Lane, H. Y., and Lin, C. H. (2018). Medications used for cognitive enhancement in patients with schizophrenia, bipolar disorder, Alzheimer's disease, and Parkinson's disease. Front. Psychiatry 9:91. doi: 10.3390/ polym 10080890

Huang, Y. J., Lin, C. H., Lane, H. Y., and Tsai, G. E. (2012). NMDA neurotransmission dysfunction in behavioral and psychological symptoms of Alzheimer's disease. Curr. Neuropharmacol. 10, 272-285. doi: 10.2174/157015912803217288

Huang, C. C., Wei, I. H., Huang, C. L., Chen, K. T., Tsai, M. H., Tsai, P., et al. (2013). Inhibition of glycine transporter-I as a novel mechanism for the treatment of depression. Biol. Psychiatry 74, 734-741. doi: 10.1016/j. biopsych.2013.02.020

Hye, A., Kerr, F., Archer, N., Foy, C., Poppe, M., Brown, R., et al. (2005). Glycogen synthase kinase-3 is increased in white cells early in Alzheimer's disease. Neurosci. Lett. 373, 1-4. doi: 10.1016/j.neulet.2004.10.031

Ikonomidou, C., and Turski, L. (2002). Why did NMDA receptor antagonists fail clinical trials for stroke and traumatic brain injury? Lancet Neurol. 1, 383-386. doi: 10.1016/S1474-4422(02)00164-3

Ilani, T., Ben-Shachar, D., Strous, R. D., Mazor, M., Sheinkman, A., Kotler, M., et al. (2001). A peripheral marker for schizophrenia: increased levels of D3 dopamine receptor mRNA in blood lymphocytes. Proc. Natl. Acad. Sci. USA 98, 625-628. doi: 10.1126/science.1058645

Kalisch, R., Holt, B., Petrovic, P., De Martino, B., Kloppel, S., Buchel, C., et al. (2009). The NMDA agonist D-cycloserine facilitates fear memory consolidation in humans. Cereb. Cortex 19, 187-196. doi: 10.1093/cercor/bhn076

Kanai, Y., and Hediger, M. A. (2004). The glutamate/neutral amino acid transporter family SLC1: molecular, physiological and pharmacological aspects. Pflugers Arch. - Eur. J. Physiol. 447, 469-479. doi: 10.1080/09629350400008810
Kumar, A. (2015). NMDA receptor function during senescence: implication on cognitive performance. Front. Neurosci. 9:473. doi: 10.1002/cld.502

Kuriyama, K., Honma, M., Koyama, S., and Kim, Y. (2011a). D-cycloserine facilitates procedural learning but not declarative learning in healthy humans: a randomized controlled trial of the effect of D-cycloserine and valproic acid on overnight properties in the performance of non-emotional memory tasks. Neurobiol. Learn. Mem. 95, 505-509. doi: 10.1016/j.nlm.2011.02.017

Kuriyama, K., Honma, M., Shimazaki, M., Horie, M., Yoshiike, T., Koyama, S., et al. (2011b). An N-methyl-D-aspartate receptor agonist facilitates sleepindependent synaptic plasticity associated with working memory capacity enhancement. Sci. Rep. 1:127. doi: 10.1038/srep00127

Labhart, A. (2012). Clinical endocrinology: Theory and practice: (Springer Science \& Business Media), 512. ISBN 978-3-642-96158-8. https://www.springer.com/ us/book/9783642961588

Lane, H. Y., Chang, Y. C., Liu, Y. C., Chiu, C. C., and Tsai, G. E. (2005). Sarcosine or D-serine add-on treatment for acute exacerbation of schizophrenia: a randomized, double-blind, placebo-controlled study. Arch. Gen. Psychiatry 62, 1196-1204. doi: 10.1101/sqb.2005.70.049

Lane, H. Y., Huang, C. L., Wu, P. L., Liu, Y. C., Chang, Y. C., Lin, P. Y., et al. (2006). Glycine transporter I inhibitor, N-methylglycine (sarcosine), added to clozapine for the treatment of schizophrenia. Biol. Psychiatry 60, 645-649. doi: 10.1016/j.biopsych.2006.04.005

Lane, H. Y., Lin, C. H., Green, M. F., Hellemann, G., Huang, C. C., Chen, P. W., et al. (2013). Add-on treatment of benzoate for schizophrenia: a randomized, double-blind, placebo-controlled trial of D-amino acid oxidase inhibitor. JAMA Psychiatry 70, 1267-1275. doi: 10.1001/jamapsychiatry.2013.2159

Lane, H. Y., Lin, C. H., Huang, Y. J., Liao, C. H., Chang, Y. C., and Tsai, G. E. (2010). A randomized, double-blind, placebo-controlled comparison study of sarcosine (N-methylglycine) and D-serine add-on treatment for schizophrenia. Int. J. Neuropsychopharmacol. 13, 451-460. doi: 10.1017/ S1461145709990939

Lane, H. Y., Liu, Y. C., Huang, C. L., Chang, Y. C., Liau, C. H., Perng, C. H., et al. (2008). Sarcosine (N-methylglycine) treatment for acute schizophrenia: a randomized, double-blind study. Biol. Psychiatry 63, 9-12. doi: 10.3233/ BIO-2009-1072

Lee, P. E., Gill, S. S., Freedman, M., Bronskill, S. E., Hillmer, M. P., and Rochon, P. A. (2004). Atypical antipsychotic drugs in the treatment of behavioural and psychological symptoms of dementia: systematic review. BMJ 329:75. doi: 10.1007/10.1007/s10616-004-5123-3

Lemini, C., Silva, G., Timossi, C., Luque, D., Valverde, A., Gonzalez-Martinez, M., et al. (1997). Estrogenic effects of p-hydroxybenzoic acid in CD1 mice. Environ. Res. 75, 130-134. doi: 10.1006/enrs.1997.3782

Lin, C. H., Chang, Y. C., Huang, Y. J., Chen, P. W., Yang, H. T., and Lane, H. Y. (2018a). Sodium benzoate, a D-amino acid oxidase inhibitor, added to clozapine for the treatment of schizophrenia: a randomized, double-blind, placebo-controlled trial. Biol. Psychiatry 84, 422-432. doi: 10.1016/j.biopsych.2017.12.006

Lin, C. H., Chen, P. K., Chang, Y. C., Chuo, L. J., Chen, Y. S., Tsai, G. E. et al. (2014). Benzoate, a D-amino acid oxidase inhibitor, for the treatment of early-phase Alzheimer disease: a randomized, double-blind, placebocontrolled trial. Biol. Psychiatry 75, 678-685. doi: 10.1016/j.biopsych.2013.08.010

Lin, C. H., Lane, H. Y., and Tsai, G. E. (2012). Glutamate signaling in the pathophysiology and therapy of schizophrenia. Pharmacol. Biochem. Behav. 100, 665-677. doi: 10.1016/j.pbb.2011.03.023

Lin, C. H., Lin, C. H., Chang, Y. C., Huang, Y. J., Chen, P. W., Yang, H. T., et al. (2018b). Sodium benzoate, a D-amino acid oxidase inhibitor, added to clozapine for the treatment of schizophrenia: a randomized, double-blind, placebo-controlled trial. Biol. Psychiatry 84, 422-432. doi: 10.1016/j. biopsych.2017.12.006

Lin, C. H., Lin, E., and Lane, H. Y. (2017a). Genetic biomarkers on age-related cognitive decline. Front. Psychiatry 8:247. doi: 10.3389/fpsyt.2017.00247

Lin, C. H., Yang, H. T., Chiu, C. C., and Lane, H. Y. (2017b). Blood levels of D-amino acid oxidase vs. D-amino acids in reflecting cognitive aging. Sci. Rep. 7:14849. doi: 10.1038/s41598-017-13951-7

Lowe, S. L., Bowen, D. M., Francis, P. T., and Neary, D. (1990). Ante mortem cerebral amino acid concentrations indicate selective degeneration of glutamateenriched neurons in Alzheimer's disease. Neuroscience 38, 571-577. doi: 10.1042/bj2720621

Lu, J. M., Gong, N., Wang, Y. C., and Wang, Y. X. (2012). D-Amino acid oxidase-mediated increase in spinal hydrogen peroxide is mainly responsible 
for formalin-induced tonic pain. Br. J. Pharmacol. 165, 1941-1955. doi: 10.1111/j.1476-5381.2011.01680.x

Marcoli, M., Bonfanti, A., Roccatagliata, P., Chiaramonte, G., Ongini, E., Raiteri, M., et al. (2004). Glutamate efflux from human cerebrocortical slices during ischemia: vesicular-like mode of glutamate release and sensitivity to $\mathrm{A}(2 \mathrm{~A})$ adenosine receptor blockade. Neuropharmacology 47, 884-891. doi: 10.1016/j. neuropharm.2004.06.022

Martinez, M., Frank, A., Diez-Tejedor, E., and Hernanz, A. (1993). Amino acid concentrations in cerebrospinal fluid and serum in Alzheimer's disease and vascular dementia. J. Neural Transm. Park. Dis. Dement. Sect. 6, 1-9.

McCarthny, C. R., Du, X., Wu, Y. C., and Hill, R. A. (2018). Investigating the interactive effects of sex steroid hormones and brain-derived neurotrophic factor during adolescence on hippocampal NMDA receptor expression. Int. J. Endocrinol. 2018:7231915. doi: 10.1155/2018/7231915

McGilvray, D., and Morris, J. G. (1969). Utilization of L-threonine by a species of Arthrobacter. A novel catabolic role for "aminoacetone synthase". Biochem. J. 112, 657-671. doi: 10.1042/bj1120657

McRoberts, J. A., Li, J., Ennes, H. S., and Mayer, E. A. (2007). Sex-dependent differences in the activity and modulation of $\mathrm{N}$-methyl-d-aspartic acid receptors in rat dorsal root ganglia neurons. Neuroscience 148, 1015-1020. doi: 10.1016/j.neuroscience.2007.07.006

Nagata, Y. (1992). Involvement of D-amino acid oxidase in elimination of D-serine in mouse brain. Experientia 48, 753-755. doi: 10.1080/00071669208417539

Nakazawa, T., Komai, S., Watabe, A. M., Kiyama, Y., Fukaya, M., Arima-Yoshida, F., et al. (2006). NR2B tyrosine phosphorylation modulates fear learning as well as amygdaloid synaptic plasticity. EMBO J. 25, 2867-2877. doi: 10.1523/ JNEUROSCI.2801-06.2006

Nebel, R. A., Aggarwal, N. T., Barnes, L. L., Gallagher, A., Goldstein, J. M., Kantarci, K., et al. (2018). Understanding the impact of sex and gender in Alzheimer's disease: a call to action. Alzheimer's and Dement. 14, 1171-1183. doi: $10.1098 /$ rsta.2018.0103

O'Brien, J. (2003). Behavioral symptoms in vascular cognitive impairment and vascular dementia. Int. Psychogeriatr. 15(Suppl. 1), 133-138. doi: 10.1017/ S1041610203009098

Olney, J. W., and Farber, N. B. (1995). Glutamate receptor dysfunction and schizophrenia. Arch. Gen. Psychiatry 52, 998-1007. doi: 10.1016/0893-133X (95)00079-S

Onur, O. A., Schlaepfer, T. E., Kukolja, J., Bauer, A., Jeung, H., Patin, A., et al. (2010). The N-methyl-D-aspartate receptor co-agonist D-cycloserine facilitates declarative learning and hippocampal activity in humans. Biol. Psychiatry 67, 1205-1211. doi: 10.1016/j.biopsych.2010.01.022

Oranje, B., Gispen-de Wied, C. C., Verbaten, M. N., and Kahn, R. S. (2002). Modulating sensory gating in healthy volunteers: the effects of ketamine and haloperidol. Biol. Psychiatry 52, 887-895. doi: 10.1016/S1081-1206(10)62123-0

Paulsen, J. S., Salmon, D. P., Thal, L. J., Romero, R., Weisstein-Jenkins, C., Galasko, D., et al. (2000). Incidence of and risk factors for hallucinations and delusions in patients with probable AD. Neurology 54, 1965-1971. doi: 10.1212/WNL.54.10.1965

Pestka, J. J., and Delwiche, E. A. (1981). 2-phosphoglycerate phosphatase and serine biosynthesis in Veillonella alcalescens. Can. J. Microbiol. 27, 808-814. doi: $10.1139 / \mathrm{m} 81-125$

Pimplikar, S. W., Nixon, R. A., Robakis, N. K., Shen, J., and Tsai, L. H. (2010). Amyloid-independent mechanisms in Alzheimer's disease pathogenesis. J. Neurosci. 30, 14946-14954. doi: 10.1523/JNEUROSCI.4305-10.2010

Prince, M., Ali, G. C., Guerchet, M., Prina, A. M., Albanese, E., and Wu, Y. T. (2016). Recent global trends in the prevalence and incidence of dementia, and survival with dementia. Alzheimers Res. Ther. 8:23. doi: 10.1186/s13195-016-0188-8

Procter, A. W., Wong, E. H., Stratmann, G. C., Lowe, S. L., and Bowen, D. M. (1989). Reduced glycine stimulation of [3H]MK-801 binding in Alzheimer's disease. J. Neurochem. 53, 698-704. doi: 10.1111/j.1471-4159.1989.tb11760.x

Randolph, C., Roberts, J. W., Tierney, M. C., Bravi, D., Mouradian, M. M., and Chase, T. N. (1994). D-cycloserine treatment of Alzheimer disease. Alzheimer Dis. Assoc. Disord. 8, 198-205.

Reisberg, B., Doody, R., Stoffler, A., Schmitt, F., Ferris, S., and Mobius, H. J. (2003). Memantine in moderate-to-severe Alzheimer's disease. N. Engl. J. Med. 348, 1333-1341. doi: 10.1017/S1041610203009256

Ritchie, K., and Kildea, D. (1995). Is senile dementia "age-related" or "ageingrelated"?-Evidence from meta-analysis of dementia prevalence in the oldest old. Lancet 346, 931-934.
Savva, G. M., Zaccai, J., Matthews, F. E., Davidson, J. E., McKeith, I., and Brayne, C. (2009). Prevalence, correlates and course of behavioural and psychological symptoms of dementia in the population. Br. J. Psychiatry 194, 212-219. doi: 10.1192/bjp.bp.108.049619

Schneider, L. S., Dagerman, K. S., and Insel, P. (2005). Risk of death with atypical antipsychotic drug treatment for dementia: meta-analysis of randomized placebo-controlled trials. JAMA 294, 1934-1943. doi: 10.1007/ s10406-005-0163-0

Schneider, L. S., Tariot, P. N., Dagerman, K. S., Davis, S. M., Hsiao, J. K., Ismail, M. S., et al. (2006). Effectiveness of atypical antipsychotic drugs in patients with Alzheimer's disease. N. Engl. J. Med. 355, 1525-1538. doi: 10.1056/NEJMoa061240

Schwartz, B. L., Hashtroudi, S., Herting, R. L., Schwartz, P., and Deutsch, S. I. (1996). d-Cycloserine enhances implicit memory in Alzheimer patients. Neurology 46, 420-424.

Serrano, F., and Klann, E. (2004). Reactive oxygen species and synaptic plasticity in the aging hippocampus. Ageing Res. Rev. 3, 431-443. doi: 10.1016/j. arr.2004.05.002

Shah, A., and Allen, H. (1999). Is improvement possible in the measurement of behaviour disturbance in dementia? Int. J. Geriatric Psychiatry 14, 512-519.

Shankar, G. M., Bloodgood, B. L., Townsend, M., Walsh, D. M., Selkoe, D. J., and Sabatini, B. L. (2007). Natural oligomers of the Alzheimer amyloid-beta protein induce reversible synapse loss by modulating an NMDA-type glutamate receptor-dependent signaling pathway. J. Neurosci. 27, 2866-2875. doi: 10.1523/ JNEUROSCI.4970-06.2007

Sink, K. M., Holden, K. F., and Yaffe, K. (2005). Pharmacological treatment of neuropsychiatric symptoms of dementia: a review of the evidence. JAMA 293, 596-608. doi: 10.1097/01.bpo.0000164872.44195.4f

Smith, C. C., Vedder, L. C., Nelson, A. R., Bredemann, T. M., and McMahon, L. L. (2010). Duration of estrogen deprivation, not chronological age, prevents estrogen's ability to enhance hippocampal synaptic physiology. Proc. Natl. Acad. Sci. USA 107, 19543-19548. doi: 10.1073/pnas.1009307107

Snyder, E. M., Nong, Y., Almeida, C. G., Paul, S., Moran, T., Choi, E. Y., et al. (2005). Regulation of NMDA receptor trafficking by amyloid-beta. Nat. Neurosci. 8, 1051-1058. doi: 10.1016/j.jpurol.2004.10.001

Steenblock, D. (2018). Treatment of behavior disturbances with ketamine in a patient diagnosed with major neurocognitive disorder. Am. J. Geriatric Psychiatry 26, 711-714. doi: 10.1073/pnas.1814072115

Stegman, L. D., Zheng, H., Neal, E. R., Ben-Yoseph, O., Pollegioni, L., Pilone, M. S., et al. (1998). Induction of cytotoxic oxidative stress by D-alanine in brain tumor cells expressing Rhodotorula gracilis D-amino acid oxidase: a cancer gene therapy strategy. Hum. Gene Ther. 9, 185-193. doi: 10.1089/ hum.1998.9.2-185

Steinberg, M., Shao, H., Zandi, P., Lyketsos, C. G., Welsh-Bohmer, K. A., Norton, M. C., et al. (2008). Point and 5-year period prevalence of neuropsychiatric symptoms in dementia: the Cache County Study. Int. J. Geriatric Psychiatry 23, 170-177. doi: 10.3928/01477447-20080401-35

Stewart, R. J., Chen, B., Dowlatshahi, D., MacQueen, G. M., and Young, L. T. (2001). Abnormalities in the cAMP signaling pathway in post-mortem brain tissue from the Stanley Neuropathology Consortium. Brain Res. Bull. 55, 625-629. doi: 10.1002/0471142956.cy0602s00

Straub, R. E., Lipska, B. K., Egan, M. F., Goldberg, T. E., Callicott, J. H., Mayhew, M. B., et al. (2007). Allelic variation in GAD1 (GAD67) is associated with schizophrenia and influences cortical function and gene expression. Mol. Psychiatry 12, 854-869. doi: 10.1039/b706926j

Takehara, K., Kawahara, S., Munemoto, Y., Kuriyama, H., Mori, H., Mishina, M., et al. (2004). The N-methyl-D-aspartate (NMDA)-type glutamate receptor GluRepsilon2 is important for delay and trace eyeblink conditioning in mice. Neurosci. Lett. 364, 43-47. doi: 10.1016/j.humpath.2004.07.020

Tardiolo, G., Bramanti, P., and Mazzon, E. (2018). Overview on the effects of $\mathrm{N}$-acetylcysteine in neurodegenerative diseases. Molecules 23. doi: 10.3390/ molecules23123305

Tariot, P. N., Farlow, M. R., Grossberg, G. T., Graham, S. M., McDonald, S., and Gergel, I. (2004). Memantine treatment in patients with moderate to severe Alzheimer disease already receiving donepezil: a randomized controlled trial. JAMA 291, 317-324. doi: 10.1001/jama.291.3.317

Thompson, C., Brodaty, H., Trollor, J., and Sachdev, P. (2010). Behavioral and psychological symptoms associated with dementia subtype and severity. Int. Psychogeriatr. 22, 300-305. doi: 10.1017/S1041610209991220 
Tomita, H., Vawter, M. P., Walsh, D. M., Evans, S. J., Choudary, P. V., Li, J., et al. (2004). Effect of agonal and postmortem factors on gene expression profile: quality control in microarray analyses of postmortem human brain. Biol. Psychiatry 55, 346-352. doi: 10.1002/cbdv.200490097

Tsai, G. E., Falk, W. E., and Gunther, J. (1998). A preliminary study of D-cycloserine treatment in Alzheimer's disease. J. Neuropsychiatr. Clin. Neurosci. 10, 224-226. doi: 10.1007/BF02920157

Tsai, G. E., Falk, W. E., Gunther, J., and Coyle, J. T. (1999). Improved cognition in Alzheimer's disease with short-term D-cycloserine treatment. Am. J. Psychiatry 156, 467-469.

Tsai, C. H., Huang, H. C., Liu, B. L., Li, C. I., Lu, M. K., Chen, X., et al. (2014). Activation of N-methyl-D-aspartate receptor glycine site temporally ameliorates neuropsychiatric symptoms of Parkinson's disease with dementia. Psychiatry Clin. Neurosci. 68, 692-700. doi: 10.1021/jz5020532

Tsai, G., Lane, H. Y., Yang, P., Chong, M. Y., and Lange, N. (2004). Glycine transporter I inhibitor, N-methylglycine (sarcosine), added to antipsychotics for the treatment of schizophrenia. Biol. Psychiatry 55, 452-456. doi: 10.1016/j. icvts.2004.08.005

Tsang, S. W., Vinters, H. V., Cummings, J. L., Wong, P. T., Chen, C. P., and Lai, M. K. (2008). Alterations in NMDA receptor subunit densities and ligand binding to glycine recognition sites are associated with chronic anxiety in Alzheimer's disease. Neurobiol. Aging 29, 1524-1532. doi: 10.1111/j. 1365-294X.2008.03907.x

Tsuang, M. T., Nossova, N., Yager, T., Tsuang, M. M., Guo, S. C., Shyu, K. G., et al. (2005). Assessing the validity of blood-based gene expression profiles for the classification of schizophrenia and bipolar disorder: a preliminary report. Am. J. Med. Genet. Part B Neuropsychiatr. Genet. 133B, 1-5. doi: 10.1002/ajmg.b.30161

Tzang, R. F., Chang, Y. C., Tsai, G. E., and Lane, H. Y. (2016). Sarcosine treatment for oppositional defiant disorder symptoms of attention deficit hyperactivity disorder children. J. Psychopharmacol. Oct 30, 976-982. doi: $10.1177 / 0269881116658986$

Van den Berghe-Snorek, S., and Stankovich, M. T. (1985). Thermodynamic control of D-amino acid oxidase by benzoate binding. J. Biol. Chem. 260, 3373-3379.

Vanoni, M. A., Cosma, A., Mazzeo, D., Mattevi, A., Todone, F., and Curti, B. (1997). Limited proteolysis and X-ray crystallography reveal the origin of substrate specificity and of the rate-limiting product release during oxidation of $\mathrm{D}$-amino acids catalyzed by mammalian $\mathrm{D}$-amino acid oxidase. Biochemistry 36, 5624-5632.

Vedder, L. C., Bredemann, T. M., and McMahon, L. L. (2014). Estradiol replacement extends the window of opportunity for hippocampal function. Neurobiol. Aging 35, 2183-2192. doi: 10.1016/j.eururo.2014.08.011

Vigen, C. L., Mack, W. J., Keefe, R. S., Sano, M., Sultzer, D. L., Stroup, T. S., et al. (2011). Cognitive effects of atypical antipsychotic medications in patients with Alzheimer's disease: outcomes from CATIE-AD. Am. J. Psychiatry 168, 831-839. doi: 10.1176/appi.ajp.2011.08121844

Waziri, R., Mott, J., and Wilcox, J. (1985). Differentiation of psychotic from nonpsychotic depression by a biological marker. J. Affect. Disord. 9, 175-180. doi: 10.1016/0165-0327(85)90098-9

Weiss, M. D., Rossignol, C., Sumners, C., and Anderson, K. J. (2005). A $\mathrm{pH}$-dependent increase in neuronal glutamate efflux in vitro: possible involvement of ASCT1. Brain Res. 1056, 105-112. doi: 10.1016/j. brainres.2005.07.045

Wilcock, G. K., Ballard, C. G., Cooper, J. A., and Loft, H. (2008). Memantine for agitation/aggression and psychosis in moderately severe to severe Alzheimer's disease: a pooled analysis of 3 studies. J. Clin. Psychiatry 69, 341-348. doi: $10.3233 / J A D-2008-15404$

Wisden, W., and Seeburg, P. H. (1993). Mammalian ionotropic glutamate receptors. Curr. Opin. Neurobiol. 3, 291-298. doi: 10.1016/0014-5793(93)80368-5

Wolosker, H., Blackshaw, S., and Snyder, S. H. (1999). Serine racemase: a glial enzyme synthesizing $\mathrm{D}$-serine to regulate glutamate-N-methyl-D-aspartate neurotransmission. Proc. Natl. Acad. Sci. USA 96, 13409-13414. doi: 10.1073/ pnas.96.23.13409

Yamin, G. (2009). NMDA receptor-dependent signaling pathways that underlie amyloid beta-protein disruption of LTP in the hippocampus. J. Neurosci. Res. 87, 1729-1736. doi: 10.1021/bi901325g

Yao, L., and Zhou, Q. (2017). Enhancing NMDA receptor function: recent progress on allosteric modulators. Neural Plast. 2017:2875904. doi: 10.1155/ 2017/2875904

Zhao, M. G., Toyoda, H., Lee, Y. S., Wu, L. J., Ko, S. W., Zhang, X. H., et al. (2005). Roles of NMDA NR2B subtype receptor in prefrontal long-term potentiation and contextual fear memory. Neuron 47, 859-872. doi: 10.1016/j. talanta.2005.02.032

Zhou, T., Wang, J., Xin, C., Kong, L., and Wang, C. (2019). Effect of memantine combined with citalopram on cognition of BPSD and moderate Alzheimer's disease: a clinical trial. Exp. Ther. Med. 17, 1625-1630. doi: 10.3892/ etm.2018.7124

Conflict of Interest Statement: The authors declare that the research was conducted in the absence of any commercial or financial relationships that could be construed as a potential conflict of interest.

Copyright (c) 2019 Lin and Lane. This is an open-access article distributed under the terms of the Creative Commons Attribution License (CC BY). The use, distribution or reproduction in other forums is permitted, provided the original author(s) and the copyright owner(s) are credited and that the original publication in this journal is cited, in accordance with accepted academic practice. No use, distribution or reproduction is permitted which does not comply with these terms. 